\title{
Allergens from Edible Insects: Cross-reactivity and Effects of Processing
}

\author{
Laura De Marchi ${ }^{1} \cdot$ Andrea Wangorsch ${ }^{2} \cdot$ Gianni Zoccatelli ${ }^{1}$ (D)
}

Accepted: 26 April 2021 / Published online: 30 May 2021

(C) The Author(s) 2021

\begin{abstract}
Purpose of Review The recent introduction of edible insects in Western countries has raised concerns about their safety in terms of allergenic reactions. The characterization of insect allergens, the sensitization and cross-reactivity mechanisms, and the effects of food processing represent crucial information for risk assessment.

Recent Findings Allergic reactions to different insects and cross-reactivity with crustacean and inhalant allergens have been described, with the identification of new IgE-binding proteins besides well-known pan-allergens. Depending on the route of sensitization, different potential allergens seem to be involved. Food processing may affect the solubility and the immunoreactivity of insect allergens, with results depending on species and type of proteins. Chemical/enzymatic hydrolysis, in some cases, abolishes immunoreactivity.

Summary More studies based on subjects with a confirmed insect allergy are necessary to identify major and minor allergens and the role of the route of sensitization. The effects of processing need to be further investigated to assess the risk associated with the ingestion of insect-containing food products.
\end{abstract}

Keywords Edible insects $\cdot$ Food allergy $\cdot$ Tropomyosin $\cdot$ Arginine kinase $\cdot$ Cross-reactivity $\cdot$ Food processing

\section{Introduction}

The Food and Agriculture Organization of the United Nations estimated that by 2050 , the world's population would reach about 9 billion people $[1,2]$, raising concerns about the capacity to feed such a large population. To solve this problem, alternative and more sustainable food sources from the economic and environmental points of view are necessary.

In this scenario, insects represent one of the most promising solutions. Insects are considered a source of nutrients like polyunsaturated fatty acids, essential amino acids, micronutrients, and protein [3]. In addition, entomophagy might have various positive implications in terms of

This article is part of the Topical Collection on Allergens

Gianni Zoccatelli

gianni.zoccatelli@univr.it

1 Department of Biotechnology, University of Verona, Verona, Italy

2 Molecular Allergology, Paul-Ehrlich-Institut, Langen, Germany sustainability. Indeed, in comparison to livestock, breeding insect produces lower greenhouse gas emissions and water pollution and is characterized by higher feed conversion efficiency and lower land dependency [1,2]. Furthermore, it is possible to utilize several plants and organic wastes as feed [4-6].

However, some risks may stem from the consumption of insects, essentially due to possible chemical (e.g., heavy metals accumulation) and microbiological contaminations. Some insects have also been reported to cause allergic reactions through inhalation, direct contact, sting/bite, and also by ingestion [2, 4, 7-9]. The adverse reactions described after the ingestion of insects can be caused by cross-reactivity with other taxonomically related food allergens like crustaceans $[10-12,13 \cdot 0]$, but also with inhalant allergens such as house dust mites (HDM) [14]. The rationale is based on the presence of common allergens among invertebrates, like tropomyosin (TM), arginine kinase (AK), and glyceraldehyde 3-phosphate dehydrogenase (GAPDH) [14, 15].

Allergic reactions to edible insects have been mainly described in Asian [16-19] and in African [20-22] countries, where entomophagy is a habitual practice. In some cases, the reactions occurred in non-atopic subjects, suggesting that 
the mechanism was based on primary sensitization to insect allergens [23, 24].

To hide the unappealing nature of eating whole insects, in Europe and in general in Western countries, these are mainly employed as ingredients to enrich fortified products. This poses interesting questions about the possible effects that different technological processes and food matrices (starch, proteins, etc.) may have on IgE-binding epitopes and how this could influence their susceptibility to gastrointestinal digestion.

Basing on research articles, clinical, and case reports, this review aims to (1) analyze the cross-reactivity of edible insects with other food and inhalant/indoor allergens, (2) evaluate the role of primary sensitization, and (3) characterize the effects that food processing might have on main cross-reactive allergens.

\section{Novel Foods and EU Legislation}

Edible insects are considered novel foods, i.e., foods that had not been consumed to a significant degree by humans in the EU before 15 May 1997. In 2018, the latest EU regulation on novel foods came into force, with the result that all the novel foods need to follow a centralized approval system, which comprises a complete risk assessment, performed by the European Food Safety Agency (EFSA), including the allergenic risks. Due to different interpretations of previous EU legislation dealing with foods and novel foods (EU REG 258/97 and 1169/2011) by European countries [25, 26], products containing edible insects were already present on the markets of some member states (Belgium, UK, the Netherland, and Denmark) before 2018. With the latest regulation, it was clarified that all the products containing edible insects which were already on the market might continue to be sold until they are approved through the new centralized procedure, but not later than January 2020. This authorization has been recently extended [27•]. Until now, the following insect species are present in the summary of applications to the European Commission: house cricket (Acheta domesticus) as powder or ground form, lesser mealworm (Alphitobius diaperinus) as whole and ground larvae products, banded crickets (Gryllodes sigillatus) in dried form, migratory locust (Locusta migratoria) as whole and ground insect, and dried yellow mealworm (Tenebrio molitor) in larval or adult stage. It can be observed that the families of Gryllidae (cricket) and Tenebrionidae (mealworm) seem to attract the major interest of the food industries. Figure 1 shows a summarized classification of the species discussed in the present review.

\section{Cross-reactivity and Primary Sensitization}

Many proteins have been discussed to play a role in the elicitation of allergic reactions after the ingestion of edible insects
[7], and, according to Barre and collaborators [28], there are pan-allergens widespread in invertebrate groups which belong to a limited number of protein families. The reviewed literature relates to two main topics: the characterization of potential insect allergens compared to the already well-known allergens using allergic patients' sera and the route of sensitization to verify whether insect allergens may act as primary sensitizers.

\section{Cross-reactivity Between Insects and Other Arthropods: General Overview}

As presented in the database of allergen families (AllFam database, http://www.meduniwien.ac.at/allfam), the most important and widely described insect allergen is tropomyosin [29], a protein-based on an alpha-helical structure involved in muscular contraction. The most relevant source of TM, as an officially accepted allergen, is represented by shellfish, i.e., crustaceans, mollusks, and cephalopods (see Pedrosa et al. [30] as a representative review), but also parasites/nematodes, like the herring worm Anisakis simplex or common roundworms Ascaris lumbricoides, contain TM described and accepted as food allergens, e.g., Ani s 3 [31] and Asc 13 [32]. Up to now, 16 arthropod TM have been registered as food allergens, according to WHO/IUIS allergen nomenclature subcommittee. Tropomyosin is also a very common and widespread inhalant allergen, with cockroaches and mites (e.g., house dust mites and storage mites) as major sources [33, 34, 35•, 36]. All known TM share a common three-dimensional structure and are characterized by high amino acid (AA)-sequence identity. The other crucial invertebrate-pan allergen is arginine kinase, a protein with enzymatic function and a highly conserved amino acid sequence among various invertebrate species [28] characterized by a $\beta$-sheet domain surrounded by $\alpha$-helices [37]. Up to now, according to the WHO-IUIS, AK from 13 species have been accepted as allergens ( 6 as airborne allergens and 7 as food ones), ranging from mites (Der f 20, Der p 20, Tyr p 20) to cockroaches (Bla g 9, Per a 9) up to shellfish (Lit v 2 and Pen $\mathrm{m}$ 2) and moths (Plo i 1). Besides these two major allergens, several potentially clinically relevant allergenic proteins from edible insects are described in the literature. In many studies, in vitro assays (e.g., immunoblotting, BAT) have been performed to analyze the cross-reactivity between insect proteins (major or minor allergens) and already well-known allergens, in most of the cases using sera of patients allergic to shrimp, mites, or other invertebrates. The co-sensitization to yellow mealworm (YMW) in crustacean allergic patients has been widely demonstrated $[14,38]$. An extensive study on the potential allergenic YMW proteins by Barre et al. [39•], including a shrimp allergic population and a second group of HDM allergic subjects with confirmed Der $\mathrm{p} 10$ sensitization, revealed a high number of potentially allergenic proteins in 


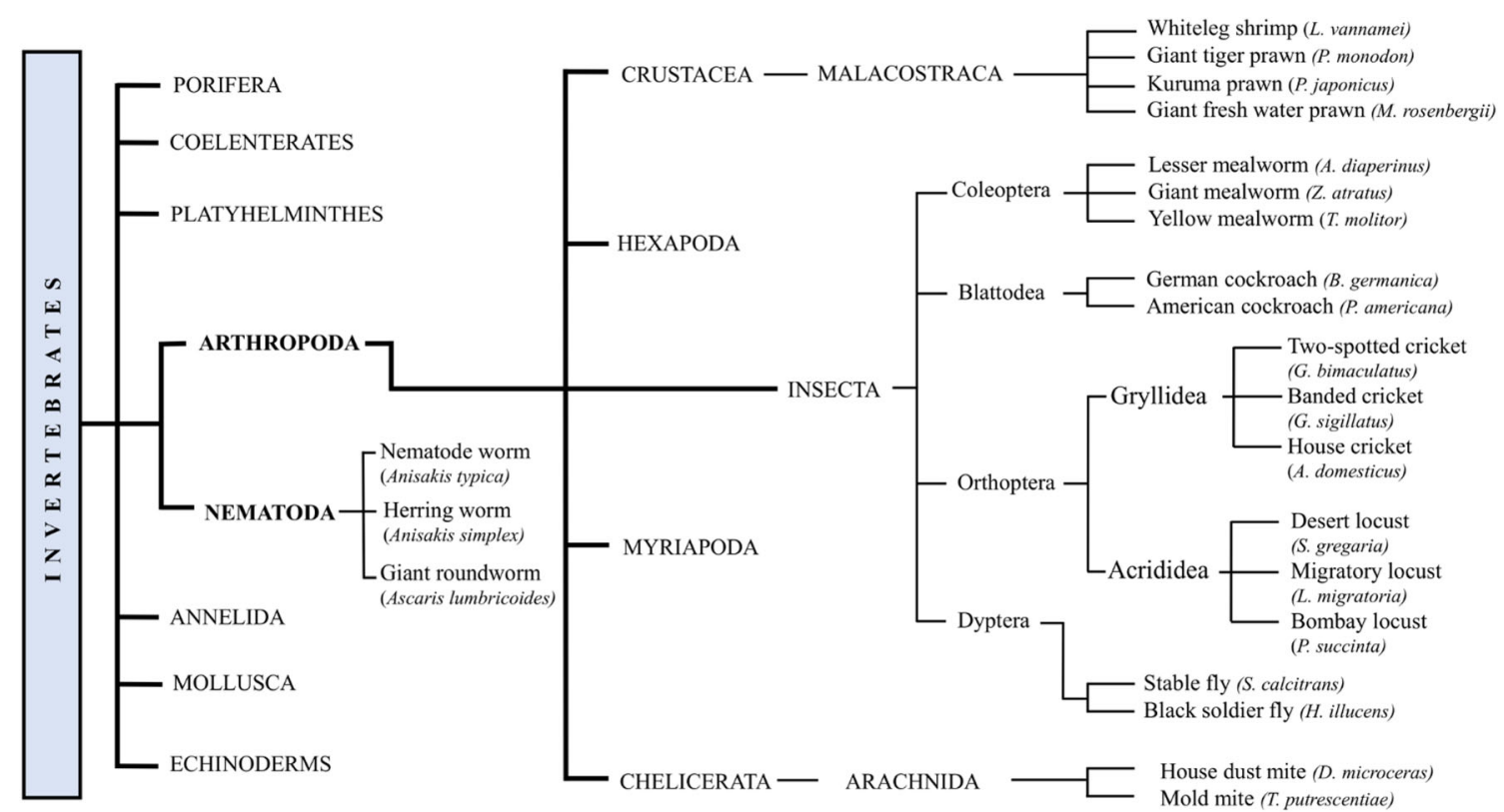

Fig. 1 Simplified classification of the insect species discussed in the present review

Tenebrio molitor. In addition to the already discussed $\alpha$ amylase [14], AK [14], TM [14, 40], and heat shock protein (HSP) 70 [14], apolipophorin-III (apoLp-III), larval cuticle protein (LCP), and a 12-kDa hemolymph protein were detected by the IgE of shrimp allergic patients [39•]. Apolipophorins until now have only been described as inhalant allergens from mites. It is still a matter of debate whether the primary inhalant allergy to invertebrates could lead to a so-called secondary food allergy, as already described for the pollen-food syndrome [35•].

Besides the pan-allergen $\mathrm{AK}$, other allergens were identified in silkworm (Bombix mori): Jeong and collaborators [41] described a $27-\mathrm{kDa}$ glycoprotein as a possible allergenic protein, though IgE reactivity using silkworm allergic patients sera was low. Zhao et al. [19] indicated chitinase and paramyosin as two other potential allergens. Chitinase has already been discussed as an allergen between different species, especially in plant kingdom, like fruits [42]. AK from silkworm (SW) is of particular relevance because it is the only allergen (Bomb $\mathrm{m} 1$ ) from edible insects officially accepted as food allergen (www.allergen.org) and included in the IUIS allergen database. Bomb $\mathrm{m} 1$ was introduced into the database in 2010 by Liu and colleagues [43], who showed that $25 \%$ of patients claiming allergic symptoms to SW or silk products were positive by skin prick test (SPT) to crude extracts from SW. All ten patients were sensitized to recombinant Bomb m 1 [43]. Although Liu et al. did not clearly define the route of exposure leading to SW allergy in this patient cohort, Bomb $\mathrm{m} 1$ was accepted as a food allergen, as SW is commonly used in traditional Asian cuisine and can lead to anaphylactic reactions $[16,44]$.

Very few studies were carried out on cricket proteins' cross-reactivity in patients allergic to shellfish or HDM. AK and hexamerin 1B (HEX1B) were identified in Gryllus bimaculatus by Srinroch and collaborators [15] as major and minor allergens, respectively, using prawn allergic patient' sera. However, Kamemura et al. [13••] indicated TM as a cross-reactive allergen between shrimp and crickets. In their study, they performed immunoblotting and a competitive inhibition ELISA using sera from 9 subjects allergic to shrimp, showing that a cricket protein of $40 \mathrm{kDa}$ (identified as a high molecular weight tropomyosin isoform) reacts with shrimpallergic patients sera $[13 \cdot \bullet]$. However, due to the limited sensitivity of the method, the authors did not exclude the presence of other cross-reactive allergens. The study of Pali-Scholl et al. [45**] not only confirmed the cross-reactivity between crustaceans and cricket (Acheta domesticus) proteins but showed that crustacean-, HDM-, and stable flies-allergic patients cross-recognize cricket proteins. Other possible insects that could lead to allergic cross-reaction in crustacean-, HDM-, and flies-allergic patients are locusts (Locusta migratoria and Schistocerca gregaria), as suggested by PaliScholl in the same work $[45 \bullet \cdot]$.

\section{Sequence Analysis}

Besides using immunoenzymatic methods, the analysis of sequence identity or homology between insect proteins and the already well-characterized food allergens (e.g., from crustaceans) gives the possibility to infer common properties shared by allergenic proteins and maybe predict the allergenic potential [46]. Although at the moment there is no clue about the structural characteristics underlying allergenicity [42], this approach is part of the risk assessment procedure indicated by EFSA for novel food proteins. Indeed, no validated or 
predictive method for the assessment of allergenicity of a novel protein or protein-containing product is globally recognized. For this reason, for the latest novel foods submissions and the preliminary safety evaluation of novel proteins, parts of the GMO allergenicity risk assessment guidelines drafted by EFSA have been used [47]. This procedure, the so-called weight-of-evidence approach, is based on an integrated caseby-case approach. The WHO guidelines for predicting allergenic cross-reactivity suggest a threshold of $35 \%$ of sequence identity to a known allergen using a sliding window of 80 amino acids [48 ${ }^{\bullet}$, or a complete identity within an 8 amino acid peptide [49]. An example of allergenicity assumption through sequence alignment analysis is the study of Liu and collaborators [43] on Bombix mori AK. Due to the significant similarity (ranging from 81 to $92 \%$ ) shared with the other AK associated with allergenic reactions and the extremely low evalues resulting from the comparison, particularly with Plo I 1 and Pen $\mathrm{m}$ 2, it can be concluded that AK of Bombix mori possesses allergenic potency.

The high sequence identity and the already extensively investigated IgE-cross reactivity between TM, AK, and other allergens from different species, like shellfish, cockroach, mites, and parasites, lead to the assumption that the same group of proteins share cross-reactive IgE-epitopes, capable of inducing allergic reactions upon consumption of insects. However, cross-reactivity seems not to be systematic. Francis et al. [50••] investigated the cross-reactivity of AK from A. domesticus and T. molitor in subjects exposed to edible insects, and no cross-reaction phenomena were observed, although AK from different insects are acknowledged to share high sequence identity ( $70 \%$ on average) and homology (90\% on average) [37]. Small differences in the sequences could likely cause a differential IgE binding, as Palmer and collaborators also stated [51••]. This could be the reason for the absence of cross-reactivity observed by Francis and coworkers $[50 \bullet \bullet$.

It has to be taken into consideration that, although the amino acid identity between two compared structures correlates with the probability of cross-reactivity, the mere amino acid identity and the structural homology are weak predictors and should be used prudently [48•,51••]. Thus, EFSA guidelines suggest additional clinical tests, like SPT or basophils activation test (BAT), and the golden standard to determine the absence/presence of allergenicity, i.e., the double-blind placebo-controlled food challenge (DBPCFC) [47, 52]. In general, data on allergenic risk due to insect consumption are very limited, as most of the trials have been conducted with a scarce number of participants $(n<20)$ [53]. To our knowledge, the only complete allergenicity study on edible insects is the one conducted by Broekman and collaborators [52]. The study was performed on a group of 15 shrimp allergic patients characterized by SPT, BAT, and immunoblotting and subsequently included in a DBCPFC trial with blanched YMW
(T. molitor). None of the patients knowingly consumed YMW proteins. The results achieved showed that 14 out of 15 patients were sensitized to YMW TM and/or AK, and 13 out of 15 reacted positively to the oral test. Eleven patients out of 12 were sensitized to TM of other species, like Anisakis, HDM, and cockroach, and to Bomb m 1, probably due to the proteins' high sequence identity. This result contributed to the complete risk evaluation of dried YMW as a novel food, published on 12 January 2021 by EFSA scientific network [54]. The expert panel concluded that the insect is safe under the proposed uses and use levels; however, in the proposed conditions, the ingestion may induce primary sensitization and allergic reactions or cause cross-reactivity phenomena in subjects allergic to crustaceans and HDM. This publication is the first complete evaluation at the European level on an edible insect as a novel food. Thus, the dried YMW will be likely be included in the European Novel food catalog.

\section{Need of Standardization}

An important aspect that has to be considered is the fact that most of the studies based on immunoblotting, BAT, and/or ELISA techniques described the sensitization of patients allergic to shellfish/inhalant allergens (e.g., cockroach or mites) to protein extracts derived from edible insects $[11,13 \bullet \bullet, 15,45 \bullet$, $51 \bullet \bullet]$, and in some cases also to purified proteins [50•*]. As claimed by Broekman et al. [55], particular attention should be paid to the extract preparation because this could modify the representative set of proteins. Indeed, Verhoeckx et al. [14] demonstrated that using Tris buffer or urea solutions, different sets of proteins could be extracted from YMW. Due to this variability, there is a great need for studies that include SPT or DBPCFC to confirm insect allergic patients and to prove that proteins expressed in edible insects, independently if already described as allergens or belonging to a completely new protein family, can elicit allergic reactions and not only showing IgE-cross-reactivity (sensitization) without causing symptoms.

\section{Primary Sensitization}

A question still open is whether the type of primary sensitization route is important for the IgE-cross reactivity of pan-allergens. Allergens from the same protein groups are accepted as allergens, for example, from shellfish and HDM or cockroaches. However, shellfish and crustacean allergens are real food allergens, as they lead to sensitization via the ingestion route, while mite and cockroach allergies are caused by the sensitization through inhalation of allergenic proteins. Although it is well known that pollen allergens, acting as a primary sensitizer, could lead to a secondary food allergy (e.g., pollen-fruit syndrome based on pathogenesis-related 
proteins 10 (PR-10), profilins, and lipid transfer proteins (PR14) [56]), it is not necessarily true for other allergen families, like tropomyosins or arginine kinases. Using patient groups without clear allergic reactions to edible insects does not help to understand whether the latter can act as primary sensitizers. To our knowledge, the only study showing the sensitizing capacity of insects was carried out employing mice and administering by gavage a YMW extract in combination with cholera toxin as adjuvant [57]. In this study, Broekman and collaborators found IgE against several proteins in 2 out of 6 mice tested, such as larval cuticle protein (A1A, A2B, A3A), $\mathrm{TM}$, actin, and AK. Unfortunately, other sensitization studies performed in rats and guinea pigs did not return statistically relevant results [58-60]. Barre et al. [39•] could show that $95 \%(20 / 21)$ of patients with anaphylaxis to shrimp are sensitized to YMW extract, whereas only 15\% (2/13) of Der p 10 positive HDM-allergic patients showed sensitization to YMW. Even if the mite allergic patients were preselected to Der p 10, and tropomyosin could clearly be detected in the YMW extract via mass spectrometry (MS) analysis, the sensitization to tropomyosin was very low. Similar findings were published by van Broekhoven et al. [40], where a pool of sera of patients allergic to HDM did not recognize TM of three different MW species extracts. In contrast, crustacean allergic patients clearly showed sensitization to tropomyosin in the same extracts. The identity degree between Der p 10 and YMW TM and between Lit $\mathrm{v} 1$ and YMW TM are very similar, i.e., 66 and 70\% respectively (https://blast.ncbi.nlm. nih.gov), but differences in crucial sequences of epitopes regions might explain the differences observed in terms of cross-reactivity, as suggested Palmer and co-workers [51••].

Occupational allergies should also be considered in this scenario. It is known that SW and mealworm breeders, as well as people exposed to locusts, could raise inhalant allergy against other insects $[61,62 \cdot \bullet, 63-65]$. Would they also react after eating edible insects? Broekman et al. [57] conducted an interesting study on subjects with a history of clinical symptoms after domestic or professional exposure to YMW and that as well consumed some insects. The results showed that a longer exposure period or the ingestion of higher doses is required to develop food allergy to mealworms. Moreover, since 3 out of 4 studied subjects showed higher levels of IgE to mealworms than to any other food or inhalant allergens they are allergic to, the authors considered that mealworms could act as the primary sensitizer, even if larval cuticular proteins, instead of TM and AK, seems to play the main role in primary mealworms allergy. In a further study, the same authors suggested the possibility that the sensitization to insects might be species-specific, meaning that allergies to different insects could be caused by specific proteins and thus mealworms-sensitized subjects are not supposed to react to all insects [11].

\section{Effect of Processing on Edible Insects' Potential Allergens}

As already said above, part of the risk assessment for novel foods includes the weight-of-evidence approach to prevent the introduction of an allergenic protein into a food source. However, this strategy is not applicable to predict the primary sensitization potency of a protein when there are no subjects with a history of sensitization to the target protein [47]. Another important consideration is that the allergenic potency of a food protein is probably influenced by factors such as food processing and the interaction with the matrix [66]. These factors are central in the case of edible insects since the most likely way of consumption in Western countries is in the form of ingredients to enrich processed foods.

Insects intended for food formulations are necessarily subjected to post-harvest processing, e.g., blanching, pasteurization, and sterilization [45••] to ensure their microbiological safety. It is well known that heat processing could affect the allergenic potency of proteins [67]. However, the effect is not predictable and could result in an enhancement of the potency, like in the case of peanut proteins, or in a reduction/ elimination of the IgE-binding capacity, e.g., tree nut allergens $[55,66,68]$. Limited information concerning the effects of processing on the allergenicity of insect proteins is available, but due to the close taxonomic relationship of insects to shellfish, it can be assumed that the alterations should be similar to those observable on shellfish $[10,55]$. Unfortunately, also studies on the effects of processing on shellfish (and in particular crustaceans) proteins are contradictory: some authors reported no significant differences in shrimp allergenicity after boiling $[69,70]$, while others observed an increased IgEbinding capacity [71-73]. However, the impact of treatment on the IgE-binding capacity does not necessarily correlate with clinical symptoms.

A few studies on the effect of different thermal treatments on edible insects (mealworms, SW, and locusts) have been conducted (see Table 1), and recently, also the impact of technological processes such as enzymatic hydrolysis has been investigated as a tool to reduce the allergenicity of different

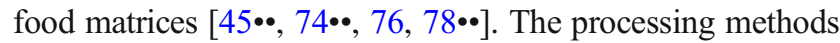
applied in the case of mealworms affected the solubility of IgE-binding proteins without, in general, decreasing their immunoreactivity. This could be due to structural modifications and aggregation phenomena, as in the case of TM that is supposed to interact with the muscle protein matrix [55]. The heat treatment of SW reduced the immunoreactivity of IgE-binding proteins. These showed different digestion profiles depending on the enzymes employed. Proteins in the 25 $33 \mathrm{kDa}$ range displayed greater stability to heat treatments and digestion $[74 \bullet \bullet]$.

The immunoreactivity of migratory locust was lost after severe heat treatments or by enzymatic hydrolysis [45••]. 


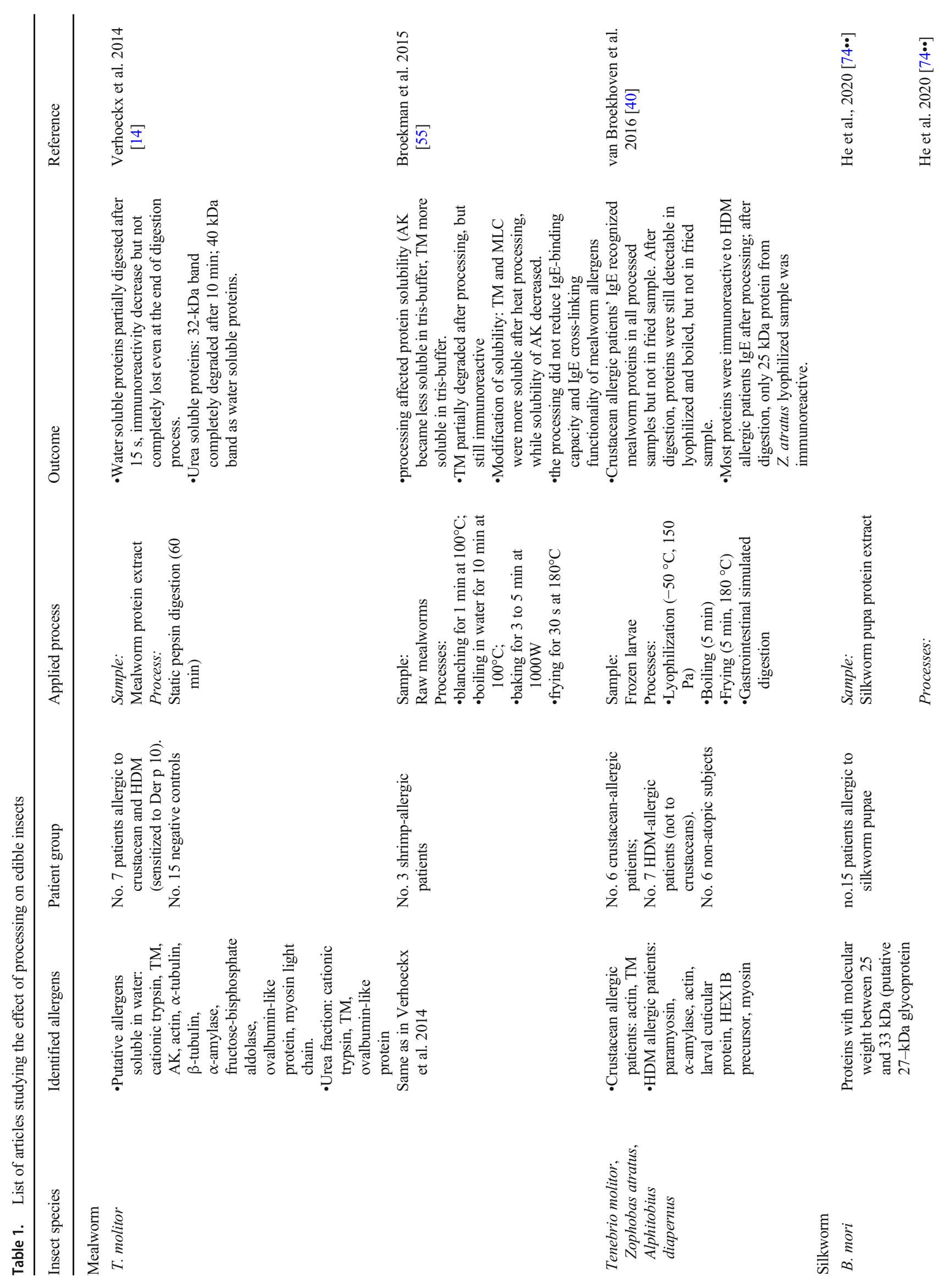




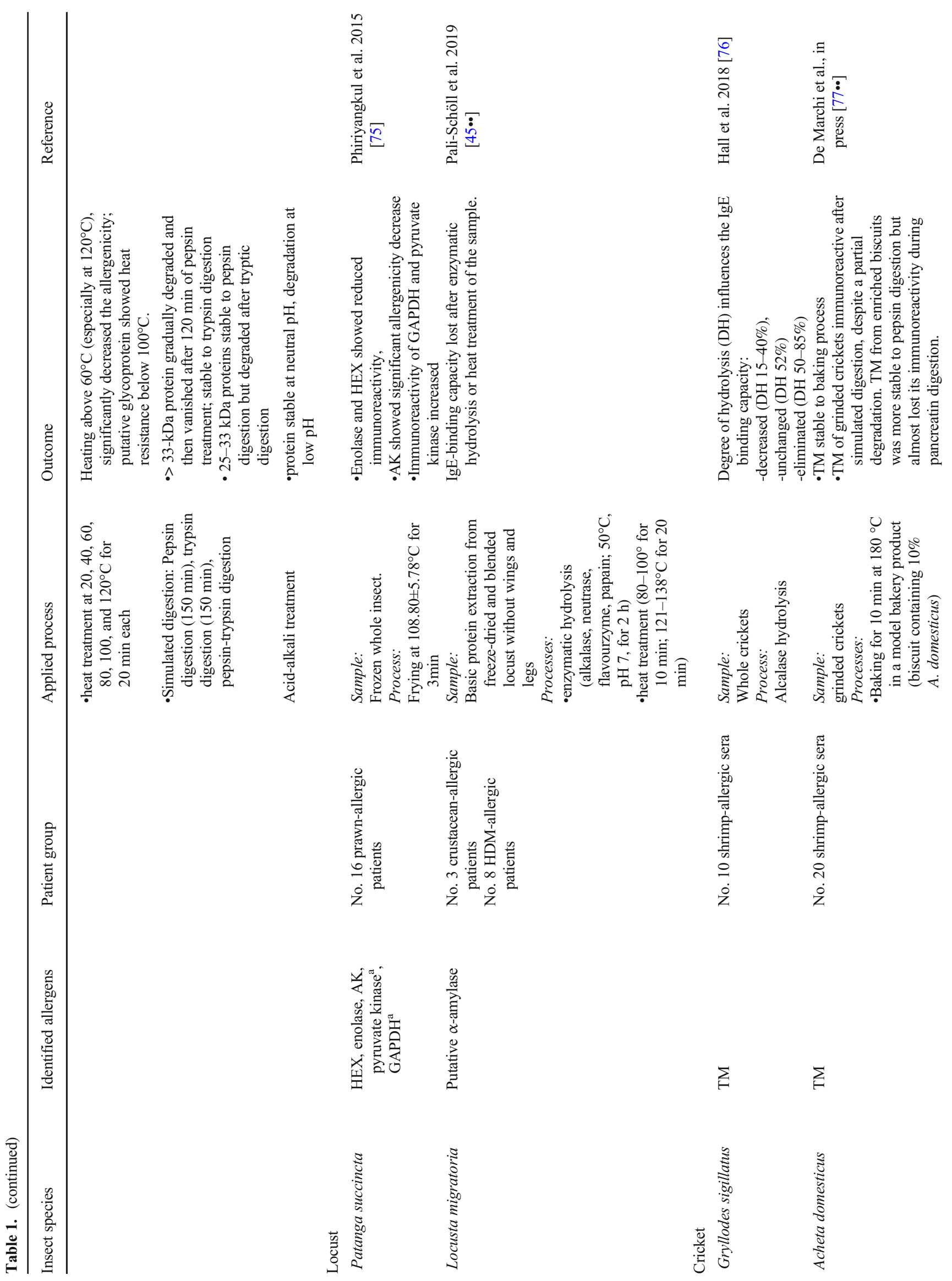




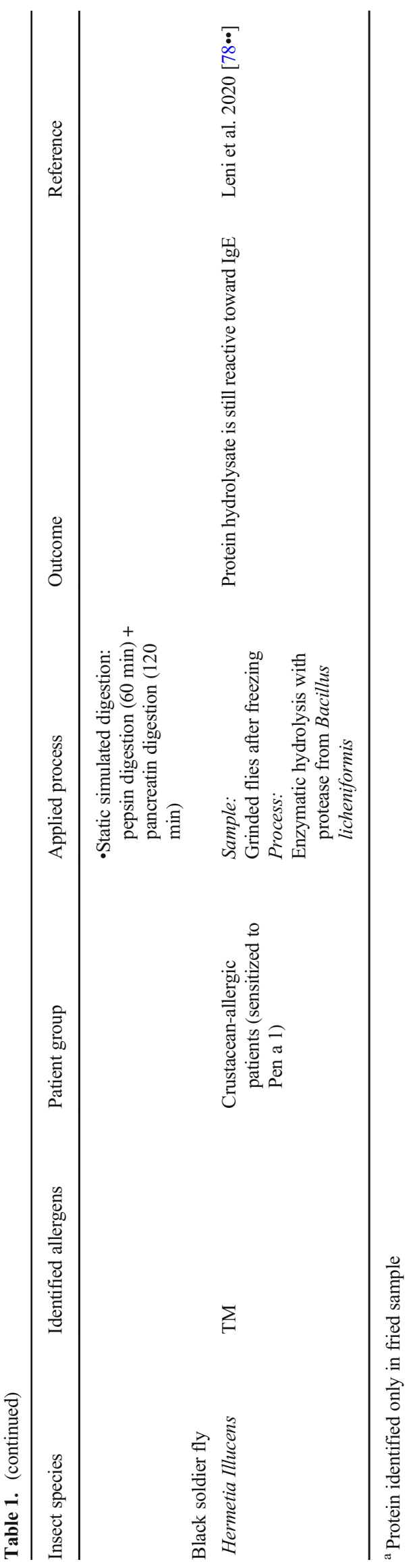

The frying treatment of Patanga succincta, another kind of locust, reduced the immunoreactivity of AK, enolase, and HEX, while GAPDH and pyruvate kinase showed higher reactivity [75]. With respect to crickets, an enzymatic treatment with alcalase abolished the relativity of TM in homogenized Gryllodes sigillatus [76]. The IgE-binding capacity of Acheta domesticus TM was still immunoreactive after simulated digestion. The baking process of a model enriched food improved the stability of TM in the gastric phase [77••].

The treatment of black soldier fly by a protease from Bacillus licheniformis to reduce the allergenicity did not abolish the immunoreactivity of the proteins [78••].

Studies that use protein extracts cannot be considered exhaustive since heating a food matrix (e.g., the whole shrimp muscle or a complex food matrix) has reasonably different effects compared to the treatment of water extracts or purified proteins. Indeed, other food components may interact with the allergens changing their solubility and structure and thus affecting IgE epitopes. The consumption of insects mainly occurs in eastern countries, where they are usually ingested as raw or after a simple food processing, such as frying and boiling. Therefore, the majority of the allergenicity studies focused on these processed forms. Differently, insects have been introduced in Western countries as ingredients of enriched foods, such as snacks [79, 80], pasta [81], and meat preparations like sausages [82] in order to be more acceptable by the consumer. For the preparation of many industrial products several food processing methods are used, e.g., different drying methods, ultra-high temperature (UHT), and short-time pasteurization [66]. One of the most convenient, productive, and cost-effective ways to produce snacks is by extrusion. This technology utilizes a single screw or a set of screws to force mixed food ingredients through a small opening. During the process, foods are cooked, and the setting of the conditions allows to obtain a final product with a precise shape and to increase characteristics like solubility, viscosity, or swelling power [83]. Evidence that this process can decrease the allergenic potency of legumes, for instance, is available. Indeed, Franck et al. [84] indicated that specific soybean allergens lost their reactivity after the texturization of soybean by extrusion. Recently, Zheng and collaborators [85॰] studied the effect of extrusion on soybean and corn meal proteins concluding that all the extruded proteins seem to show a lower immunoreactivity compared to the raw materials. Moreover, the circular dichroism analysis of the proteins showed that the processing leads to a structural conformation shift to a more $\beta$-strandbased structure [85•]. This evidence may have important implications in the reduction of the allergenic potency of insect proteins incorporated into extruded formulations. TM possesses a characteristic alfa-helical structure that may be affected by the extrusion process. Furthermore, the addition of other starchy ingredients like cereal or legume flours, commonly employed in this process, may lead to the establishment of 
interactions between the insect proteins and the matrix, differently impacting on the epitopes. We think that this hypothesis should be further investigated.

Food matrix may affect not only the allergenic potency of a protein but also its susceptibility to digestion. In fact, Schulten and collaborators [86] investigated whether the presence of a food matrix could influence the absorption of model allergens (from cow milk and hazelnut) after gastrointestinal digestion. The group concluded that a food matrix rich in protein and carbohydrates could hamper the degradation of allergens during the digestion process. Van Broekhoven et al. [40] studied the effect of processing and in vitro digestion on allergic cross-reactivity of MW extract in HDM allergic patients. Proteins underwent boiling, frying, and lyophilization. The major allergen (TM) seems to be stable to boiling and to in vitro digestion, while the allergenicity seems to be decreased after frying, which would confirm that the type of processing method influences the allergenic potency of an allergen [40].

Another important consideration about the incorporation of insect derivates in food preparations concerns the effective amount of insect protein resulting in the final product. As stated by Garino and collaborators [27•], the allergenic risk would be associated with the consumption of a reasonable serving size, but the actual content of protein in a serving size is highly variable. In their study, the authors considered foods containing different percentages of mealworm protein, and, basing on the doseresponse curve elaborated by Broekman and collaborators [52], they identified a possible eliciting dose. With the currently available data, it is not possible to define a general threshold dose, but authors suggest that a few milligrams of insect tropomyosin could be able to elicit a clinical response in shrimp sensitized individuals, and this dose is far lower than the whole hypothetical serving size [27•]. Spanjerserber and collaborators [87] propose an alternative quantitative risk assessment model based on probabilistic techniques, which returns a more exhaustive risk assessment and detailed information. The method permits the prediction of the possible severity of the reaction associated with the presence of a food allergen in a product and considers the allergen intake as a variable that influences the outcome of the prediction.

\section{Conclusion}

The information available on the allergenicity of edible insects is still very limited. They can cross-react with other largely consumed foods like crustaceans but also with widespread invertebrate inhalant allergens like HDM. There is a great need for data deriving from studies based on subjects with confirmed allergy to edible insects.
This will help to understand the way of sensitization and the possible cross-reactivity with other species. Indeed, it seems that the proteins responsible for cross-reactive phenomena are different from those playing a role in the primary sensitization to species like YMW. These studies should also include tests based on single purified allergens to allow the cross-inhibition experiments between, e.g., crustaceans (food), mite, and cockroach (inhalant), and between different insect species. In case several single allergens will be available, a component-resolved diagnosis (CRD) could be performed. Only by this kind of approach it will be possible to understand the frequency of sensitization, identify major or minor allergens, and assess the risk of allergic reactions due to IgE-cross reactivity.

The effects of processing should represent another aim of future research. In this case, the processing of more realistic model foods in which insects are combined with other food ingredients in complex matrices will help to understand the possible modifications of the epitopes and how this could impact the cross-reactivity and sensitization capacity of insect allergens.

Abbreviations AK, Arginine kinase; BAT, Basophil activation test; EFSA, European Food Safety Authority; GAPDH, Glyceraldehyde 3phosphate dehydrogenase; HDM, House dust mite; HEXB1, Hexamerin 1B; HSP, Heat shock protein; IgE, Immunoglobulin E; SPT, Skin prick test; SW, Silkworm; TM, Tropomyosin; YMW, Yellow mealworm

Acknowledgements This article is based upon work from COST Action FA1402 entitled ImpARAS - Improving Allergy Risk Assessment Strategy for New Food Proteins supported by COST (www.cost.eu).

Funding Open access funding provided by Università degli Studi di Verona within the CRUI-CARE Agreement.

\section{Declarations}

Conflict of Interest The authors declare no competing interests.

Human and Animal Rights and Informed Consent This article does not contain any studies with human or animal subjects performed by any of the authors.

Open Access This article is licensed under a Creative Commons Attribution 4.0 International License, which permits use, sharing, adaptation, distribution and reproduction in any medium or format, as long as you give appropriate credit to the original author(s) and the source, provide a link to the Creative Commons licence, and indicate if changes were made. The images or other third party material in this article are included in the article's Creative Commons licence, unless indicated otherwise in a credit line to the material. If material is not included in the article's Creative Commons licence and your intended use is not permitted by statutory regulation or exceeds the permitted use, you will need to obtain permission directly from the copyright holder. To view a copy of this licence, visit http://creativecommons.org/licenses/by/4.0/. 


\section{References}

Papers of particular interest, published recently, have been highlighted as:

- Of importance

•- Of major importance

1. Kouřimská L, Adámková A. Nutritional and sensory quality of edible insects. NFS J. 2016;4:22-6. https://doi.org/10.1016/j.nfs.2016. 07.001.

2. van Huis A, Itterbeeck JV, Klunder H, Mertens E, Halloran A, Muir G, Vantomme P. Edible insect: future prospects for food and feed security. Roma: Fao forestry Papers; 2013.

3. Rumpold BA, Schlüter OK. Nutritional composition and safety aspects of edible insects. Mol Nutr Food Res. 2013;57:802-23. https:// doi.org/10.1002/mnfr.201200735.

4. Akhtar Y, Isman MB. Insects as an alternative protein source. In: Yada RY, editor. Proteins Food Process. Cambridge: Woodhead Publishing; 2018.

5. Fowles TM, Nansen C. Insect-based bioconversion: value from food waste. In: Närvänen E, Mesiranta N, Mattila M, Heikkinen A, editors. Food Waste Manag. Cham: Palgrave Macmillan; 2020.

6. van Huis A. Insects as human food. In: Nóbrega Alves RR, Albuquerque UP, editors. Ethnozoology, animals in our lives. London: Academic Press; 2018 pp. 195-213

7. de Gier S, Verhoeckx K. Insect (food) allergy and allergens. Mol Immunol. 2018;100:82-106. https://doi.org/10.1016/j.molimm. 2018.03.015.

8. Ribeiro JC, Cunha LM, Sousa-Pinto B, Fonseca J. Allergic risks of consuming edible insects: a systematic review. Mol Nutr Food Res. 2018;62:1-12. https://doi.org/10.1002/mnfr.201700030.

9. Jeong KY, Park JW. Insect allergens on the dining table. Curr Protein Pept Sci. 2020;21:159-69. https://doi.org/10.2174/ 1389203720666190715091951.

10. Downs $\mathrm{M}$, Johnson $\mathrm{P}$, Zeece $\mathrm{M}$. Insects and their connection to food allergy. In: Dossey TA, Morales-Ramos JA, Rojas MG, editors. Insects as Sustainable Food Ingredients, Production, Processing and Food Applications. London, Academic Press; 2016. pp 255-272.

11. Broekman HC, Knulst AC, de Jong G, Gaspari M, den Hartog Jager $\mathrm{CF}$, Houben GF, et al. Is mealworm or shrimp allergy indicative for food allergy to insects? Mol Nutr Food Res. 2017;61:1-9. https:// doi.org/10.1002/mnfr.201601061.

12. Belluco S, Mantovani A, Ricci A. Edible insects in a food safety perspective. In: Halloran A, Flore R, Vantomme P, Roos N, editors. Edible Insects in Sustainable Food Systems. Cham: Springer; 2018.

13•• Kamemura N, Sugimoto M, Tamehiro N, Adachi R, Tomonari S, Watanabe T, et al. Cross-allergenicity of crustacean and the edible insect Gryllus bimaculatus in patients with shrimp allergy. Mol Immunol. 2019;106:127-34. https://doi.org/10.1016/j.molimm. 2018.12.015. The authors investigated the allegenic crossreactivivity of a common cricket species with shrimp using sera from subjects allergic to shrimp, concluding that tropomyosin is the major cross-reactive allergen.

14. Verhoeckx KC, van Broekhoven S, den Hartog-Jager CF, Gaspari M, de Jong GA, Wichers HJ, et al. House dust mite (Der p 10) and crustacean allergic patients may react to food containing Yellow mealworm proteins. Food Chem Toxicol. 2014;65:364-73. https://doi.org/10.1016/j.fct.2013.12.049.

15. Srinroch C, Srisomsap C, Chokchaichamnankit D, Punyarit P, Phiriyangkul P. Identification of novel allergen in edible insect, Gryllus bimaculatus and its cross-reactivity with Macrobrachium spp. allergens. Food Chem. 2015;184:160-6. https://doi.org/10. 1016/j.foodchem.2015.03.094.
16. Ji K, Chen J, Li M, Liu Z, Wang C, Zhan Z, et al. Anaphylactic shock and lethal anaphylaxis caused by food consumption in China. Trends Food Sci Technol. 2009;20:227-31. https://doi.org/10. 1016/j.tifs.2009.02.004.

17. Jirapongsananuruk O, Bunsawansong W, Piyaphanee N, Visitsunthorn N, Thongngarm T, Vichyanond P. Features of patients with anaphylaxis admitted to a university hospital. Ann Allergy Asthma Immunol. 2007;98:157-62. https://doi.org/10. 1016/S1081-1206(10)60689-8.

18. Piromrat K, Chinratanapisit S, Trathong S. Anaphylaxis in an emergency department: a 2-year study in a tertiary-care hospital. Asian Pac J Allergy Immunol. 2008;26:121-8.

19. Zhao X, Li L, Kuang Z, Luo G, Li B. Proteomic and immunological identification of two new allergens from silkworm (Bombyx mori L.) pupae. Cent Eur J Immunol. 2015;40:30-4. https://doi.org/10. 5114/ceji.2015.50830.

20. Okezie OA, Kgomotso KK, Letswiti MM. Mopane worm allergy in a 36-year-old woman: a case report. J Med Case Rep. 2010;4:2-5. https://doi.org/10.1186/1752-1947-4-42.

21. Kung SJ, Fenemore B, Potter PC. Anaphylaxis to mopane worms (Imbrasia belina). Ann Allergy Asthma Immunol. 2011;106:538 40. https://doi.org/10.1016/j.anai.2011.02.002.

22. Kung SJ, Steenhoff AP. Allergy in Botswana. Curr Allergy Clin Immunol. 2013;26:202-9.

23. Freye HB, Esch RE, Litwin CM, Sorkin L. Anaphylaxis to the ingestion and inhalation of Tenebrio molitor (mealworm) and Zophobas morio (superworm). Allergy Asthma Proc. 1996;17: 215-9. https://doi.org/10.2500/108854196778996903.

24. Seshimo H, Ito T, Egusa C, Numata T, Kobayashi T, Abe N, Niitsuma T, Okubo Y, Harada K. A case of anaphylactic shock induced by mealworm antigen in the bite of a Japanese flying squirrel. J Eur Acad Dermatol Venereol. 2021; https://doi.org/10.1111/jdv.17265.

25. European Parliament and the Council of the European Union. Regulation (EC) No 258/97 of the European Parliament and of the council of 27 January 1991 concerning novel foods and novel food ingredients. Off J Eur Union. 1997;L 43:1-6.

26. European Parliament and the Council of the European Union. Regulation (EU) 2015/2283 of the European Parliament and of the Council of 25 October 2011 on novel foods, amending Regulation (EU) No 1169/2011 of the European Parliament and of the Council and repealing Regulation (EC) No 258/97 etc. Regulation on the provision of food information to consumers. Off J Eur Union. 2015;327:1-22.

27• Garino C, Mielke H, Knüppel S, Selhorst T, Broll H, Braeuning A. Quantitative allergenicity risk assessment of food products containing yellow mealworm ( Tenebrio molitor ). Food Chem Toxicol. 2020;142:111460. https://doi.org/10.1016/j.fct.2020.111460. The authors focused on the evaluation of the real dose of insect protein ingested with fortified food and proposed a statistic method to facilitate the assessment of allergenic risk.

28. Barre A, Simplicien M, Cassan G, Benoist H, Rougé P. Food allergen families common to different arthropods (mites, insects, crustaceans), mollusks and nematods: cross-reactivity and potential cross-allergenicity. Rev Fr Allergol. 2018;58:581-93. https://doi. org/10.1016/j.reval.2018.10.008.

29. Radauer C, Bublin M, Wagner S, Mari A, Breiteneder H. Allergens are distributed into few protein families and possess a restricted number of biochemical functions. J Allergy Clin Immunol. 2008;121:847-52. https://doi.org/10.1016/j.jaci.2008.01.025.

30. Pedrosa M, Boyano-Martínez T, García-Ara C, Quirce S. Shellfish allergy: a comprehensive review. Clin Rev Allergy Immunol. 2015;49:203-16. https://doi.org/10.1007/s12016-014-8429-8.

31. Asturias JA, Eraso E, Martínez A. Cloning and high level expression in Escherichia coli of an Anisakis simplex tropomyosin isoform. Mol Biochem Parasitol. 2000;108:263-7. https://doi.org/10. 1016/S0166-6851(00)00218-8. 
32. Acevedo N, Erler A, Briza P, Puccio F, Ferreira F, Caraballo L. Allergenicity of Ascaris lumbricoides tropomyosin and IgE sensitization among asthmatic patients in a tropical environment. Int Arch Allergy Immunol. 2011;154:195-206. https://doi.org/10.1159/ 000321106.

33. Santos ABR, Chapman MD, Aalberse RC, Vailes LD, Ferriani VPL, Oliver C, et al. Cockroach allergens and asthma in Brazil: identification of tropomyosin as amajor allergen with potential cross-reactivity with mite and shrimp allergens. J Allergy Clin Immunol. 1999;104:329-37. https://doi.org/10.1016/S0091-6749(99)70375-1.

34. Wong L, Huang CH, Lee BW. Shellfish and house dust mite allergies: is the link tropomyosin? Allergy, Asthma Immunol Res. 2016;8:101-6. https://doi.org/10.4168/aair.2016.8.2.101.

35. Faber MA, Van Gasse AL, Decuyper II, Sabato V, Hagendorens $\mathrm{MM}$, Mertens $\mathrm{C}$, et al. Cross-reactive aeroallergens: which need to cross our mind in food allergy diagnosis? J Allergy Clin Immunol Pract. 2018;6:1813-23. https://doi.org/10.1016/j.jaip.2018.08.010 In this study, the correlation of inhalant allergens from different sources and the consequent development of food allergy is presented. The authors reported that HDM-allergic subject sensitized through inhalation could experience allergic episodes also after the ingestion of food containing mites.

36. Shroba J, Rath N, Barnes C. Possible role of environmental factors in the development of food allergies. Clin Rev Allergy Immunol. 2019;57:303-11. https://doi.org/10.1007/s12016-018-8703-2.

37. Barre A, Caze-Subra S, Gironde C, Bienvenu F, Bienvenu J, Rougé P. Entomophagie et risque allergique. Rev Fr Allergol. 2014;54: 315-21. https://doi.org/10.1016/j.reval.2014.02.181.

38. Pali-Schöll I, Verhoeckx K, Mafra I, Bavaro SL, Mills EC, Monaci L. Allergenic and novel food proteins: State of the art and challenges in the allergenicity assessment. Trends Food Sci Technol. 2019;84:45-8. https://doi.org/10.1016/j.tifs.2018.03.007.

39• Barre A, Pichereaux C, Velazquez E, Maudouit A, Simplicien M, Garnier L, et al. Insights into the allergenic potential of the edible yellow mealworm (Tenebrio molitor). Foods. 2019;8. https://doi. org/10.3390/foods 8100515 . This article provides an accurate overview of potential allergenic proteins in yellow mealworm.

40. Van Broekhoven S, Bastiaan-Net S, De Jong NW, Wichers HJ. Influence of processing and in vitro digestion on the allergic crossreactivity of three mealworm species. Food Chem. 2016;196:107583. https://doi.org/10.1016/j.foodchem.2015.10.033.

41. Jeong KY, Son M, Lee JY, Park KH, Lee JH, Park JW. Allergenic characterization of $27-\mathrm{kDa}$ glycoprotein, a novel heat stable allergen, from the pupa of silkworm, Bombyx mori. J Korean Med Sci. 2016;31:18-24. https://doi.org/10.3346/jkms.2016.31.1.18.

42. Leoni C, Volpicella M, Dileo MC, Gattulli BA, Ceci LR. Chitinases as food allergens. Molecules. 2019;24:1-10. https://doi.org/10. 3390/molecules24112087

43. Liu Z, Xia L, Wu Y, Xia Q, Chen J, Roux KH. Identification and characterization of an arginine kinase as a major allergen from silkworm (Bombyx mori) larvae. Int Arch Allergy Immunol. 2009;150:8-14. https://doi.org/10.1159/000210375.

44. Gautreau M, Restuccia M, Senser K, Weisberg SN. Familial anaphylaxis after silkworm ingestion. Prehosp Emerg Care. 2017;21: 83-5. https://doi.org/10.1080/10903127.2016.1204035.

45•• Pali-Schöll I, Meinlschmidt P, Larenas-Linnemann D, Purschke B, Hofstetter G, Rodríguez-Monroy FA, et al. Edible insects: crossrecognition of $\mathrm{IgE}$ from crustacean- and house dust mite allergic patients, and reduction of allergenicity by food processing. World Allergy Organ J. 2019;12. https://doi.org/10.1016/j.waojou.2018. 10.001. The authors offer a very detailed and complete overview on insect allergy.

46. McClain S. Bioinformatic screening and detection of allergen crossreactive IgE-binding epitopes. Mol Nutr Food Res. 2017;61:1-14. https://doi.org/10.1002/mnfr.201600676.
47. Verhoeckx K, Broekman H, Knulst A, Houben G. Allergenicity assessment strategy for novel food proteins and protein sources. Regul Toxicol Pharmacol. 2016;79:118-24. https://doi.org/10. 1016/j.yrtph.2016.03.016.

48 Klueber J, Costa J, Randow S, Codreanu-Morel F, Verhoeckx K, Bindslev-Jensen C, et al. Homologous tropomyosins from vertebrate and invertebrate: recombinant calibrator proteins in functional biological assays for tropomyosin allergenicity assessment of novel animal foods. Clin Exp Allergy. 2020;50:105-16. https://doi.org/ 10.1111/cea.13503. The study provides an evaluation of the allergenicity of tropomyosins from different sources (invertebrates and vertebrates) through in vitro assays.

49. Palmer L. Edible insects as a source of food allergens. [Dissertation Theses]. [Nebraska, Ne]: University of Nebraska-Lincoln; 2016.

50• Francis F, Doyen V, Debaugnies F, Mazzucchelli G, Caparros R, Alabi T, et al. Limited cross reactivity among arginine kinase allergens from mealworm and cricket edible insects. Food Chem. 2019;276:714-8. https://doi.org/10.1016/j.foodchem.2018.10. 082 . The authors investigated the cross-reactivity properties of arginine kinase as major shrimp allergen, demonstrating the absence of cross-reactivity between the cricket $A$. domesticus and the mealworm $T$. molitor homologues.

51•• Palmer LK, Marsh JT, Lu M, Goodman RE, Zeece MG, Johnson PE. Shellfish tropomyosin IgE cross-reactivity differs among edible insect species. Mol Nutr Food Res. 2020;64:1-7. https://doi. org/10.1002/mnfr.201900923. The authors studied the variation of tropomyosin cross-reactivity among some of the most representative edible insects. They demonstrated a different degree of cross-reactivity in shrimp-allergic patient sensitized to tropomyosin when exposed to different edible insects.

52. Broekman H, Verhoeckx KC, den Hartog Jager CF, Kruizinga AG, Pronk-Kleinjan AG, Remington BC, et al. Majority of shrimp-allergic patients are allergic to mealworm. J Allergy Clin Immunol. 2016;137: 1261-3. https://doi.org/10.1016/j.jaci.2016.01.005.

53. Dobermann D, Swift JA, Field LM. Opportunities and hurdles of edible insects for food and feed. Nutr Bull. 2017;42:293-308.

54. Turck D, Castenmiller J, De Henauw S, Hirsch-Ernst KI, Kearney J, Maciuk A, et al. Safety of dried yellow mealworm (Tenebrio molitor larva) as a novel food pursuant to Regulation (EU) 2015/2283. EFSA J. 2021;19:1-29.

55. Broekman H, Knulst A, den Hartog JS, Monteleone F, Gaspari M, De Jong $\mathrm{G}$, et al. Effect of thermal processing on mealworm allergenicity. Mol Nutr Food Res. 2015;59:1855-64. https://doi.org/10. 1002/mnfr.20150013.

56. Poncet $\mathrm{P}$, Sénéchal H, Charpin D. Update on pollen-food allergy syndrome. Expert Rev Clin Immunol. Taylor \& Francis. 2020;16: 561-78. https://doi.org/10.1080/1744666X.2020.1774366.

57. Broekman HC, Knulst AC, den Hartog Jager CF, van Bilsen JH, Raymakers FM, Kruizinga AG, et al. Primary respiratory and food allergy to mealworm. J Allergy Clin Immunol. 2017;140:600-3. https://doi.org/10.1016/j.jaci.2017.01.035.

58. Noh JH, Yun EY, Park H, Jung KJ, Hwang JS, Jeong EJ, et al. Subchronic oral dose toxicity of freeze-dried powder of Allomyrina dichotoma larvae. Toxicol Res. 2015;31:69-75. https://doi.org/10. 5487/TR.2015.31.1.069.

59. Ryu HY, Lee S, Ahn KS, Kim HJ, Lee SS, Ko HJ, et al. Oral toxicity study and skin sensitization test of a cricket. Toxicol Res. 2016;32:159-73. https://doi.org/10.5487/TR.2016.32.2.159.

60. Han SR, Lee BS, Jung KJ, Yu HJ, Yun EY, Hwang JS, et al. Safety assessment of freeze-dried powdered Tenebrio molitor larvae (yellow mealworm) as novel food source: evaluation of 90-day toxicity in Sprague-Dawley rats. Regul Toxicol Pharmacol. 2016;77:20612. https://doi.org/10.1016/j.yrtph.2016.03.006.

61. Stanhope J, Carver S, Weinstein P. The risky business of being an entomologist: a systematic review. Environ Res. 2015;140:619-33. https://doi.org/10.1016/j.envres.2015.05.025. 
62•• Nebbia S, Lamberti C, Giorgis V, Giuffrida MG, Manfredi M, Marengo E, et al. The cockroach allergen-like protein is involved in primary respiratory and food allergy to yellow mealworm (Tenebrio molitor). Clin Exp Allergy. 2019;49:1379-82. The article reports two cases of occupational allergy which could be correlated to a primary sensitization to cockroach proteins.

63. Lopata AL, Kleine-Tebbe J, Kamath SD. Allergens and molecular diagnostics of shellfish allergy. Allergo J Int. 2016;25:24-32. https://doi.org/10.1007/s15007-016-1194-7.

64. Hrgovic I, Messerschmidt A, Kaufmann R, Valesky E. Occupational immediate-type reactions to locusts - a possible cross-reactivity between desert locusts (Schistocerca gregoria) and migratory locusts (Locusta migratoria)? JAAD Case Rep. 2018;4:484-5. https://doi.org/10.1016/j.jdcr.2017.11.027.

65. Bellas TE. Occupational inhalant allergy to arthropods. Clin Rev Allergy. 1990;8:15-29.

66. Sathe SK, Sharma GM. Effects of food processing on food allergens. Mol Nutr Food Res. 2009;53:970-8. https://doi.org/10.1002/ mnfr.200800194.

67. Verhoeckx KCM, Vissers YM, Baumert JL, Faludi R, Feys M, Flanagan S, et al. Food processing and allergenicity. Food Chem Toxicol. 2015;80:223-40. https://doi.org/10.1016/j.fct.2015.03. 005.

68. Maleki SJ, Chung SY, Champagne ET, Raufman JP. The effects of roasting on the allergenic properties of peanut proteins. J Allergy Clin Immunol. 2000;106:763-8. https://doi.org/10.1067/mai.2000. 109620.

69. Samson KT, Chen FH, Miura K, Odajima Y, Iikura Y, Rivas MN, et al. IgE binding to raw and boiled shrimp proteins in atopic and nonatopic patients with adverse reactions to shrimp. Int Arch Allergy Immunol. 2004;133:225-32. https://doi.org/10.1159/ 000076828.

70. Usui M, Harada A, Ishimaru T, Sakumichi E, Saratani F, SatoMinami C, et al. Contribution of structural reversibility to the heat stability of the tropomyosin shrimp allergen. Biosci Biotechnol Biochem. 2013;77:948-53. https://doi.org/10.1271/bbb.120887.

71. Abramovitch JB, Kamath S, Varese N, Zubrinich C, Lopata AL, O'Hehir RE, et al. IgE reactivity of blue swimmer crab (Portunus

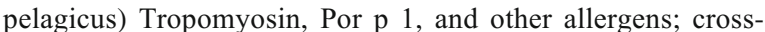
reactivity with black tiger prawn and effects of heating. PLoS One. 2013;8:1-13. https://doi.org/10.1371/journal.pone.0067487.

72. Liu GM, Cheng H, Nesbit JB, Su WJ, Cao MJ, Maleki SJ. Effects of boiling on the IgE-binding properties of tropomyosin of shrimp (Litopenaeus vannamei). J Food Sci. 2010;75:T1-5. https://doi.org/ 10.1111/j.1750-3841.2009.01391.x.

73. Nakamura A, Watanabe K, Ojima T, Ahn D, Saeki H. Effect of Maillard reaction on allergenicity of scallop tropomyosin. J Agric Food Chem. 2005;53:7559-64. https://doi.org/10.1021/jf0502045.

74•• He W, He K, Sun F, Mu L, Liao S, Li Q, et al. Effect of heat, enzymatic hydrolysis and acid-alkali treatment on the allergenicity of silkworm pupa protein extract. Food Chem. 2021;343. https:// doi.org/10.1016/j.foodchem.2020.12846. The study presents the effects of different treatments on the allergenicity of a sikworm pupa protein extract, concluding that for most of the proteins the allergenicity is reduced with the increase of temperature and low $\mathrm{pH}$ condition, and during simulated gastointestinal digestion. A putative IgE-binding glycoprotein is stable to high temperatures and to pepsin digestion.

75. Phiriyangkul P, Srinroch C, Srisomsap C, Chokchaichamnankit D, Punyarit P. Effect of food thermal processing on allergenicity proteins in Bombay locust (Patanga succincta). Int J Food Eng. 2015;1: 23-8. https://doi.org/10.18178/ijfe.1.1.23-28.

76. Hall F, Johnson PE, Liceaga A. Effect of enzymatic hydrolysis on bioactive properties and allergenicity of cricket (Gryllodes sigillatus) protein. Food Chem. 2018;262:39-47. https://doi.org/ 10.1016/j.foodchem.2018.04.058.
77•• De Marchi L, Mainente F, Leonardi M, Scheurer S, Wangorsh A, Mahler V, et al. Allergenicity assessment of the edible cricket Acheta domesticusin terms of thermal and 1gastrointestinal processing and IgE cross-reactivity with shrimp. Food Chem. 2021 In press. https://doi.org/10.1016/j.foodchem.2021.129878 The authors investigated the cross-reactivity between the cricket Acheta domesticus TM and the shrimp homologue, evaluating the effect of the baking process and simulated gastrointestinal digestion on a enriched model food.

78•• Leni G, Tedeschi T, Faccini A, Pratesi F, Folli C, Puxeddu I, et al. Shotgun proteomics, in-silico evaluation and immunoblotting assays for allergenicity assessment of lesser mealworm, black soldier fly and their protein hydrolysates. Sci Rep. 2020;10:1-10. https:// doi.org/10.1038/s41598-020-57863-5. In this article, the effect of enzymatic hydrolysis on black soldier fly tropomyosin is presented, showing that the immunoreactivity has not been abolished.

79. Azzollini D, Derossi A, Fogliano V, Lakemond CM, Severini C. Effects of formulation and process conditions on microstructure, texture and digestibility of extruded insect-riched snacks. Innov Food Sci Emerg Technol. 2018;45:344-53. https://doi.org/10. 1016/j.ifset.2017.11.017.

80. Cuj-Laines R, Hernández-Santos B, Reyes-Jaquez D, DelgadoLicon E, Juárez-Barrientos JM, Rodríguez-Miranda J. Physicochemical properties of ready-to-eat extruded nixtamalized maize-based snacks enriched with grasshopper. Int J Food Sci Technol. 2018;53:1889-95. https://doi.org/10.1111/ijfs.13774.

81. Duda A, Adamczak J, Chełmińska P, Juszkiewicz J, Kowalczewski P. Quality and nutritional/textural properties of durum wheat pasta enriched with cricket powder. Foods. 2019;8:1-10. https://doi.org/ $10.3390 /$ foods 8020046

82. Kim HW, Setyabrata D, Lee YJ, Jones OG, Kim YHB. Pre-treated mealworm larvae and silkworm pupae as a novel protein ingredient in emulsion sausages. Innov Food Sci Emerg Technol. 2016;38: 116-23. https://doi.org/10.1016/j.ifset.2016.09.023.

83. Alam MS, Kaur J, Khaira H, Gupta K. Extrusion and extruded products: changes in quality attributes as affected by extrusion process parameters: a review. Crit Rev Food Sci Nutr. 2016;56:44573. https://doi.org/10.1080/10408398.2013.779568.

84. Franck P, Vautrin DM, Dousset B, Kanny G, Nabet P, GuénardBilbaut $\mathrm{L}$, et al. The allergenicity of soybean-based products is modified by food technologies. Int Arch Allergy Immunol. 2002;128:212-9. https://doi.org/10.1159/000064254.

85 - Zheng H, Yan G, Lee Y, Alcaraz C, Marquez S, de Mejia EG. Effect of the extrusion process on allergen reduction and the texture change of soybean protein isolate-corn and soybean flour-corn mixtures. Innov Food Sci Emerg Technol. 2020;64:102421. https://doi. org/10.1016/j.ifset.2020.102421. The authors studied in detail the effect of extrusion process of corn and soy allergenic proteins. They concluded that proteins that underwent extrusion show a decreased immunoreactivity compared to the untreated samples and that the proteins folding shifts to a $\beta$-barrels structure.

86. Schulten V, Lauer I, Scheurer S, Thalhammer T, Bohle B. A food matrix reduces digestion and absorption of food allergens in vivo. Mol Nutr Food Res. 2011;55:1484-91. https://doi.org/10.1002/ mnfr.201100234.

87. Spanjersberg MQI, Kruizinga AG, Rennen MAJ, Houben GF. Risk assessment and food allergy: the probabilistic model applied to allergens. Food Chem Toxicol. 2007;45:49-54. https://doi.org/10. 1016/j.fct.2006.07.018.

Publisher's Note Springer Nature remains neutral with regard to jurisdictional claims in published maps and institutional affiliations. 